\title{
AS COMPREENSÕES INTERVENCIONISTAS DA PSICOLOGIA SOCIAL COMUNITÁRIA LATINO-AMERICANA A PARTIR DE UMA REVISÃO BIBLIOGRÁFICA E BIBLIOMÉTRICA
}

THE INTERVENTIONAL INSIGHTS OF LATIN AMERICAN COMMUNITY SOCIAL PSYCHOLOGY FROM A BIBLIOGRAPHIC AND BIBLIOMETRIC REVIEW

Isabela da Silva Pontes ${ }^{1}$

Universidade Estadual de Maringá, Maringá, Brasil

Viviani Teodoro dos Santos ${ }^{2}$

Universidade Tecnológica Federal do Paraná e

Universidade Estadual de Maringá, Brasil

Marcio Pascoal Cassandre ${ }^{3}$

Universidade Estadual de Maringá e Aarhus University, Århus ,Dinamarca

Resumo: O objetivo do estudo é investigar a incidência de propostas intervencionistas de pesquisa pela Psicologia Social Comunitária Latino-Americana (PSCLA). Realizou-se estudo bibliográfico e bibliométrico que revelou: i) baixo número de publicações, porém em Qualis A1 e A2; ii) a maioria dos estudos é apresentada na língua portuguesa; iii) número de publicações oscila conforme os anos; iv) os artigos encontrados apresentaram aparato metodológico, porém a discussão se mostrou incipiente sobre possíveis indicações de procedimentos metodológicos específicos para a PSCLA e; v) as técnicas de pesquisa mais utilizadas foram: observação e anotação em diário de campo, entrevistas e questionários.

Palavras-chave: Pesquisa intervencionista; Psicologia Social Comunitária Latino Americana.

Abstract: The objective of the study is to investigate the incidence of interventionist research proposals by the Latin American Community Social Psychology (PSCLA). A bibliographical and bibliometric study was made and it was revealed: i) low number of publications, but A1

\footnotetext{
${ }^{1}$ Graduanda em Administração, aluna da graduação em Administração em Universidade Estadual de Maringá. Email: isabela17.pontes@gmail.com.

${ }^{2}$ Graduada em Administração, aluna do mestrado em Administração do PPA-UEM. Email: vivi_adm3@hotmail.com.

${ }^{3}$ Professor do Programa de Pós-Graduação em Admininistração e do Departamento de Administração da Universidade Estadual de Maringá. Pós-doutorando na Danish School of Education. Email: mcassandre@hotmail.com. Recebido em: 30/12/2017. Aprovado em: 16/03/2018.
} 
and A2 classification; ii) most of the studies are published in Portuguese; iii) publications oscillate according to the years; iv) the articles that was found presented methodological apparatus, but the discussion was incipient about possible indications of specific methodological procedures for PSCLA and; v) that the most used research techniques were: observation and annotation in field diary, interviews and questionnaires.

Keywords: Interventional research; Social Psychology Latin American Community.

\section{INTRODUÇÃO}

O objetivo do presente estudo é investigar a incidência de propostas intervencionistas realizadas a partir dos conceitos da Psicologia Social Comunitária Latino-Americana (PSCLA). A Psicologia Social pode ser vista como um primeiro passo em direção a uma nova forma de enxergar o indivíduo, que não estava sendo mais estudado no isolamento, mas sim por meio de suas interações em sociedade. Esse movimento, porém, ainda não era suficiente para atender certas demandas sociais, fazendo com que, na década de 1960, a Psicologia Social passasse a assumir essa preocupação.

Seu início ocorre nos Estados Unidos, sendo chamada de Psicologia Comunitária (PC) ou Psicologia Comunitária Norte Americana (PCNA) e, na América Latina, por Psicologia Social Comunitária (PSC) ou Psicologia Social Latino-Americana (PSLA), ou ainda, Psicologia Social Comunitária Latino-Americana (PSCLA). Portanto, pela leitura realizada durante a pesquisa, pode-se perceber que autores fazem uso de termos diferentes para referirse a uma prática, justificando as definições apresentadas na base teórica dessa pesquisa.

Para a investigação proposta nesta pesquisa, compreende-se que os métodos intervencionistas são conhecidos por serem modelos que exigem não somente conhecimento teórico passivo, mas também uma atitude ativa, por meio de ações e métodos de aplicações. Esses métodos intervencionistas, segundo Thiollent, começaram a ganhar mais força a partir do papel importante que mostraram desempenhar em situações problemáticas (PICHETH; CASSANDRE; THIOLLENT, 2016).

Picheth, Cassandre e Thiollent (2016) ponderam que autores como Lewin argumentavam a necessidade de que as pesquisas sociais fossem voltadas à prática, ou seja, uma abordagem integrada capaz de enfrentar temas preocupantes presentes no ambiente social. Nesse contexto, o surgimento da Psicologia Social Comunitária tem o caráter voltado ao social e apresenta melhor desempenho realizando os métodos intervencionistas. 
Pessoa da Silva (2013) afirma que, para Bock, no Brasil, a Psicologia tradicional não tinha contribuições para o meio social, e em alguns casos era utilizada de forma errônea como instrumento político-ideológico pelas elites brasileiras. As mudanças que ocorreram para que surgisse a Psicologia Social foram gradativas, lentas e com dificuldade de inserção em atividades. Aguiar e Ronzani, porém, mencionam autores como Spink, que destacam como o ambiente hospitalar foi um dos primeiros que aderiram à prática (AGUIAR; RONZANI, 2007).

A Psicologia Social, entretanto, que surgiu como uma vertente da própria Psicologia, passou por crise de conceito. Gouveia (2015) destaca autores como Lane, que defendem essa manifestação a partir de diversas críticas que surgiram a respeito da dimensão metodológica, seus métodos científicos, bem como as teorias, concepções, consequências e a verdadeira relevância da Psicologia Social. Outra crítica fortemente defendida na época era a respeito de como a Psicologia Social contribuía para a manutenção das relações de poder e opressão.

Mesmo sendo uma abordagem nascida da crítica à Psicologia Social, a Psicologia Comunitária de origem norte-americana também causou descontentamento pelo fato de suas ações comunitárias estarem mais voltadas ao fortalecimento institucional do que das próprias comunidades.

Isso se deve ao fato de que esse novo modelo, alternativo ao modelo clínico, surge nos Estados Unidos, durante o governo de Kennedy, tendo como principal função a busca de soluções para o serviço de saúde mental americano. Neste sentido, poderiam ser consideradas como causas de seu surgimento: o repúdio do modelo médico; o rechaço dos hospitais psiquiátricos (desinstitucionalização); o desencanto com a psicoterapia; a desproporção entre oferta e demanda; e os novos problemas sociais (drogas, crises familiares, etc.) (VIDAL, 2007).

Este contexto histórico americano, sobretudo seu interesse em soluções políticas e institucionais, apesar de contribuir com o nascimento da Psicologia Comunitária, também apresenta pontos questionáveis. Em paralelo, psicólogos sociais da América Latina, mesmo sem saber, movidos por esse descontentamento com a Psicologia Social, passam a praticar uma nova psicologia social ativista e militante, agora voltada mais ao fortalecimento das comunidades do que das instituições. Esta abordagem latino-americana da Psicologia Social, mais tarde, será denominada como Psicologia Social Latino-Americana e Psicologia Social Comunitária Latino-Americana. 
Neste sentido, a Psicologia Social Comunitária Latino-Americana, apesar de ser uma subdisciplina da Psicologia Comunitária, nasce da Psicologia Social, em paralelo à Psicologia Comunitária Norte-Americana (MONTERO, 2004).

Câmara e Franciscatti (2016) destacam como todas as críticas apontadas na época foram ligadas a autores da tradicional Psicologia Social, tanto europeia quanto da América Latina, como Silvia Lane e Martin Baró (CÂMARA; FRANCISCATTI, 2016). Assim, nas décadas de 1960, 1970 e 1980, em regiões como a América do Norte, Europa, Ásia e América Latina, surgem diversas discussões a respeito dos limites metodológicos e epistemológicos da atuação do conceito de Psicologia Social (CRUZ; STRALEN, 2012).

Maciel e Alves (2015) destacam autores como Campos, que defende que o conceito da Psicologia Comunitária enfatiza e problematiza a aplicação de conhecimentos de forma metodológica, utilizando-se de medidas participantes (MACIEL; ALVES, 2015). Desse modo, ela tende a promover a consciência e a minimizar a alienação de uma forma participante e reflexiva nos grupos nos quais trabalha. Sendo assim, ela surge a partir do momento em que o sujeito assume um papel ativo e busca soluções para os problemas que estão relacionados com sua realidade e utilizam da Psicologia Comunitária para desenvolver alternativas sustentáveis (MACIEL; ALVES, 2015).

Stachiu e Tagliamento (2016), ponderam autores, como por exemplo Sawaia, que entende o objetivo da Psicologia Comunitária integrar indivíduos e grupos a partir da transformação de suas atitudes e ações. Tendo a Psicologia Comunitária caráter de ciência aplicada, cabe a essa produzir intervenções sociais para causar reflexão para essa transformação de atitudes e ações dos indivíduos da comunidade. Essa Psicologia Comunitária deve conter os processos de orientação de mudança social que vise desenvolver a comunidade em questão (STACHIU; TAGLIAMENTO, 2016).

Tendo em vista que a Psicologia Comunitária pensa na construção de sujeitos comunitários com característica problematizadoras (NEPOMUCENO et al., 2008), o comportamento da mesma é totalmente ligado ao caráter histórico das pessoas e do coletivo em que vive, assim como os sofrimentos e subjetividades (SILVA, 2013).

Sendo a Psicologia Comunitária tão importante para a realidade da sociedade, este estudo pretende investigar a incidência de propostas intervencionistas de pesquisa pela Psicologia Social Comunitária Latino-Americana (PSCLA). Estabelece-se como problema de pesquisa: investigação das incidências de propostas intervencionistas de pesquisa pela Psicologia Social Comunitária Latino-Americana (PSCLA)? Sendo assim, encontrar quais são 
os procedimentos metodológicos, bem como os métodos, técnicas e estratégias de pesquisa das publicações sobre PSCLA nos periódicos que tratam desta temática.

Para esse estudo vamos identificar e analisar as publicações nacionais vinculadas a periódicos Qualis A1, A2, B1 e B2 sobre pesquisas relacionadas à Psicologia Social Comunitária Latino-Americana, de forma que possamos identificar as incidências de proposta da PSCLA. Além disso, podemos destacar alguns objetivos específicos:

- Listar os periódicos nacionais que tenham recebido propostas de trabalhos que envolvam pesquisas da Psicologia Social Comunitária Latino-Americana;

- Identificar as características destas propostas considerando a forma de apresentação das mesmas- resumo, resumo expandido ou artigo completo;

- Relacionar as linhas teóricas expostas, bem como os procedimentos metodológicos, métodos, técnicas e estratégias de pesquisa das publicações pesquisadas;

- Construir um referencial teórico para futuras pesquisas empíricas sobre essa temática, a partir dos dados coletados e das informações sistematizadas.

\section{COMPREENDENDO A PSICOLOGIA SOCIAL COMUNITÁRIA LATINO- AMERICANA}

Como mencionado, a Psicologia Social Comunitária Latino-Americana surgiu principalmente como vertente de descontentamento da Psicologia Social, apresentando três grandes fatores responsáveis por seu surgimento. As repercussões da Segunda Guerra Mundial provocaram situações de crise nas relações sociais, questionamentos sobre estudos teóricos da Psicologia Social e até a reivindicação de uma ciência mais comprometida com o relacionamento social e seus pontos críticos (AZEVÊDO; PARDO, 2014).

A Psicologia Social Comunitária Latino-Americana nasce das demandas de países em situações de vulnerabilidade social e sua urgência em se aproximar e transformar essa realidade.

Uma questão importante a ser esclarecida, principalmente pelo caráter do trabalho que está sendo desenvolvido, é a utilização confusa dos termos Psicologia Comunitária (PC) e Psicologia Social Comunitária Latino-Americana (PSCLA). Isso se deve ao fato de que a PSCLA começa a se desenvolver na América Latina de maneira bastante personalizada mesmo antes de ser assim denominada. Segundo Montero (2004), na maior parte da década de 
1970 se fazia Psicologia Comunitária sem se saber, porém a ausência de um nome próprio não foi obstáculo para o seu desenvolvimento.

Neste sentido, é comum encontrar autores usando o termo PC se referindo a PCNA, outros se referindo à PSCLA, sendo possível fazer essa diferenciação apenas pela ênfase maior ou menor que se dá no texto às questões sociais. Inclusive, alguns autores latinoamericanos usam o termo PC ao invés de PSCLA, entendendo que ambas estejam interligadas e, que ao usar uma denominação mais genérica (MONTERO, 2004), abarcam as diversas tendências deste ramo da psicologia que se alimentam sempre de suas origens.

O que se observa nas leituras é que o termo PSCLA é utilizado, principalmente, quando se deseja marcar esta postura crítica em relação à PCNA, geralmente em correntes mais ativistas e militantes do campo.

A Psicologia Comunitária prioriza em sua essência a qualidade de vida das pessoas, por meio do desenvolvimento das relações comunitárias e construção de políticas sociais (AZEVÊDO; PARDO, 2014) de forma participativa, envolvida no meio humano e social por meio de novas formas de intervenções no meio comunitário.

O trabalho da Psicologia Comunitária se difere das demais Psicologias relacionadas à saúde no quesito espaço e forma de organizar essas atividades. São realizados, primeiramente, fora de consultórios e gabinetes, sendo feitos em ruas, comunidades e espaços frequentados pelo público, em que se defende relações horizontais e igualitárias e não as hierárquicas. Para a realização desses trabalhos são utilizadas outras técnicas, como recursos de expressão artística, música e teatro, tudo que possa envolver a criatividade humana. Também deve-se destacar que esses trabalhos têm o intuito de direcionar as percepções das pessoas para situações desconfortáveis do dia a dia para todas as camadas sociais (FREITAS, 2015).

Os responsáveis por esses estudos devem tomar a convivência em sociedade como raiz principal do movimento de seu estudo, compreendendo a realidade, a vida e as dimensões que possam integrar a realidade dos objetos de estudo (FREITAS, 2015). Portanto, cabe a responsabilidade de analisar a estrutura desse plano psicossocial por meio dos problemas do cotidiano, no seu enfrentamento e nas construções de ações e coletivas da comunidade (FREITAS, 2015). Autores como Oberg e Vilhena (2011) destacam, por exemplo, Marcina Golçalves por sua justificativa da importância dessa atuação da Psicologia no meio de defesa e implementação de políticas, para que seja possível uma transformação prática da realidade. 
Portanto, quando os autores falam de uma ação concreta em comunidade, estão sugerindo pressupostos de pesquisa-ação, participante, oficinas em grupos e pesquisas de intervenção (VIEIRA-SILVA, 2015).

Sendo assim, fica claro ao leitor que a prioridade da Psicologia Social Comunitária Latino-Americana está ligada às repercussões psicossociais das condições de vida dos indivíduos, construção de conhecimento e compromisso político, demonstrando que essa prática de estudo procura estimular os indivíduos para a identificação e resolução de problemas (AZEVÊDO; PARDO, 2014).

Para que esse trabalho seja realizado, a Psicologia Comunitária deve se utilizar de técnicas necessárias para colocar em prática seus objetivos. Primeiramente, deve-se ter bem estabelecido quais serão as temáticas abordadas, sua contextualização, bem como instrumentos e critérios para utilizar. Freitas (2005) destaca que é necessária, principalmente, uma perspectiva externa, ou seja, conhecimentos que ultrapassem uma análise do visível, onde deve-se atentar a aspectos mais profundos de cunho político e social da vida em cotidiano. Portanto, a forma encontrada para a implementação tem como base as intervenções sociais, ou seja, medidas participativas em que se pode ter um contato maior com esses indivíduos em comunidade.

As medidas de intervenção são importantes porque levam a ações transformadoras em que o responsável pelos estudos não compreende apenas aspectos técnicos, mas sim a dimensão ético-política que esses indivíduos estão inseridos (COIN-CARVALHO; OSTRONOFF, 2016). As medidas de participação são aquelas que possibilitam um diálogo, criação de espaços de troca de ideias e construção de opiniões (ANDRADE; VELOSO, 2015), podendo se utilizar de imagens, vídeos, filmes, dramatizações, fotografia e diversas atividades que façam essa aproximação. Nesse estilo de atividade a população tem maior participação e integração entre si, dando o espaço para que os próprios investiguem e intervenham por sua população nos problemas que enfrentam (VIEIRA-SILVA, 2015).

Para ser bem realizado, portanto, deve conter várias técnicas para o trabalho em sociedade. Picheth, Cassandre e Thiollent (2016) destacam principalmente algumas delas, em que são utilizados questionários e entrevistas e também técnicas antropológicas como observação de campo e diários. Compreender e racionalizar sobre a situação problemática proposta vai muito além, pois é necessário um entendimento do grupo, que após passar por atividades com o pesquisador, deve identificar, mapear e criar ações sobre o que identificaram. Um trabalho assim não é imposto ao grupo; juntos, irão perceber e realizar 
aquilo que consideraram como hipóteses e soluções (PICHETH; CASSANDRE; THIOLLENT, 2016).

A Psicologia Comunitária ganhou mais estudos com diversidade de práticas, fazeres, referenciais teóricos e até instrumentos que são direcionados a temáticas necessárias do cotidiano. Portanto, é mais fácil encontrar hoje estudos realizados com diferentes matrizes e orientações teórico-metodológicas (FREITAS, 2015).

O número de estudos sobre como o assunto vem sendo trabalhado e implementado nas intervenções comunitárias, porém, ainda é baixo (RIBAS JR, et al, 2009). Nesse sentido, o presente estudo pretende verificar esse dado por meio de um estudo bibliográfico e bibliométrico que tem como principal objetivo inferira incidência de propostas intervencionistas de pesquisa pela Psicologia Social Comunitária Latino-Americana (PSCLA), bem como os procedimentos metodológicos, métodos, técnicas e estratégias de pesquisa das publicações pesquisadas. .

\section{PROCEDIMENTOS METODOLÓGICOS}

O desenvolvimento da pesquisa se iniciou por meio de seleção na plataforma Sucupira (sucupira.capes.gov.br/sucupira), onde foram selecionados periódicos de classificação A1, A2, B1 e B2, considerando apenas as abas Qualis de 2014 na área de Psicologia. Esse critério de pesquisa resultou em400 periódicos que, após a sua identificação, foram acessados por meio de sites oficiais ou bases de dados científicas como Ebsco, ProQuest e Scielo. O processo de busca dos artigos se utilizou das seguintes palavras-chave: Psicologia Social Comunitária Latino-Americana, Psicologia Social Comunitária, Psicologia Social, bem como também em inglês e espanhol.

Os artigos encontrados na busca eram salvos em um banco de dados para investiga-los mais profundamente. Dos 400 periódicos classificados, somente 29 deles possuíam temas relacionados com o da pesquisa. A partir desses periódicos foram selecionados 79 artigos para compor a base literária deste estudo. Os parâmetros bibliométricos analisados foram: classificação Qualis dos periódicos, tipo de estudos, periódicos com maior número de publicações, tema abordado, teoria utilizada, evolução das publicações por ano, idioma de publicação, autores mais produtivos e técnicas utilizadas.

\section{DISCUSSÃO DOS RESULTADOS}


Após analisar os dados, entendeu-se que o tema apresenta alguns pontos que merecem atenção. Primeiro, o tema tem ganhado força ao longo dos anos. Apesar do número de publicações não ser alto, desde a primeira publicação, em 1997, este número vem crescendo. Por esta perspectiva, esses números tendem a aumentar, mesmo que atualmente somente $7,25 \%$ dos periódicos da plataforma abordem o tema. Diante disso, entende-se que o número de estudos sobre a PSCLA, apesar de escasso, vem crescendo gradativamente. Por enquanto, entende-se que os autores procuram mais entender a realidade social por meio de temas específicos ao invés de dar enfoque ao desenvolvimento teórico da temática.

Sendo assim, ao tentar identificar a incidência de propostas intervencionistas como opção metodológica nestes estudos, encontraram-se diversas técnicas, entre elas a observação e anotação em diário de campo, questionários e oficina com atividades lúdicas. Esses procedimentos são sempre mais utilizados em trabalhos que pretendem conhecer a realidade da comunidade, sua situação no dia a dia e a forma como estabelecem relacionamentos que despertem a percepção, fazendo com que realizem as mudanças necessárias. A partir da coleta dos artigos e sua leitura, observaram-se pontos importantes que ajudam na compreensão da situação atual do tema. O primeiro dado importante a ser analisado é a quantidade de periódicos que abordam o tema. Os 29 periódicos representam somente 7,25\% dos 400 periódicos classificadas na plataforma Sucupira. Sendo esses os que apresentaram artigos com os temas necessários, as análises foram baseadas em suas características.

A primeira observação que se fez presente é em relação à classificação de tais periódicos. Segue, abaixo, a figura 1, que demonstra a quantidade de classificação Qualis dos periódicos analisados:

\section{Figura 1 - Classificação dos artigos encontrados}




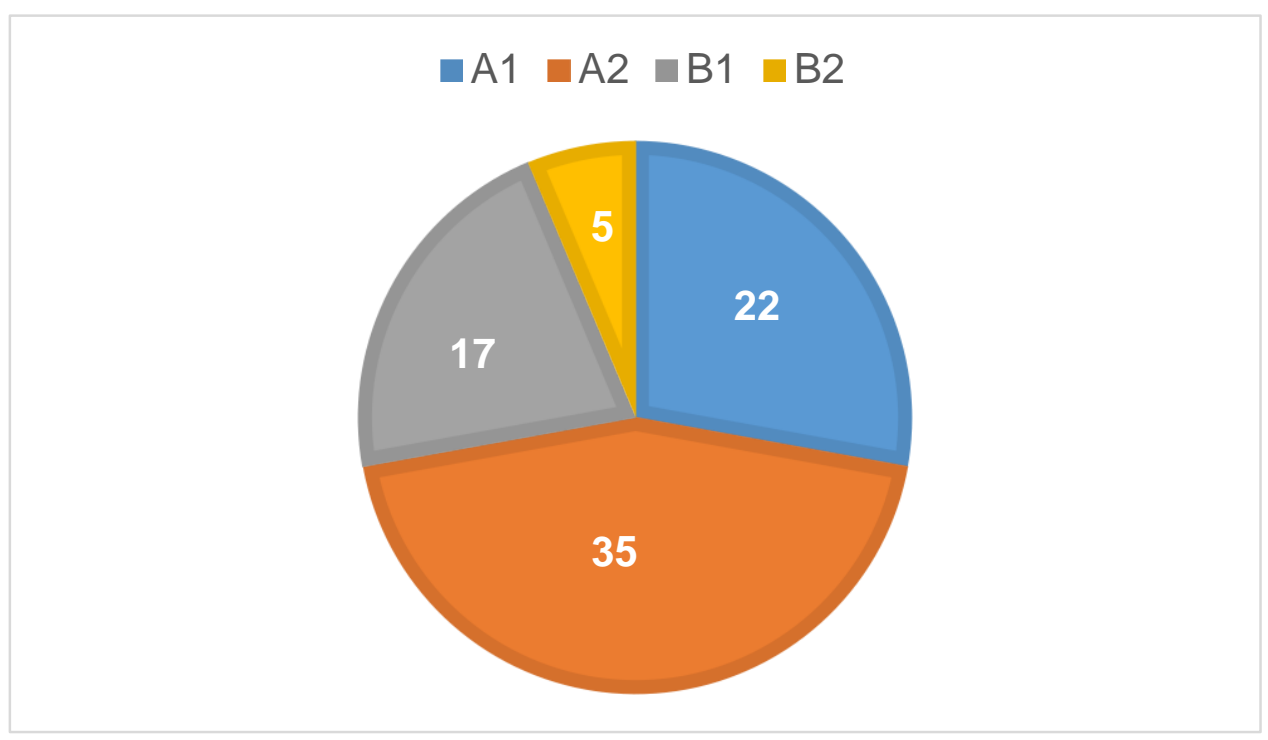

Fonte: elaborado pelos autores.

Observou-se que a maioria dos periódicos que continham o tema de interesse estão classificados em Qualis A1 e A2, ou seja, as classificações mais altas, demonstrando que os estudos relacionados à PSCLA são aprovados em revistas com maiores critérios de avaliação. Sendo assim, é possível inferir que os estudos realizados em tais artigos tem uma maior credibilidade de conteúdo, demonstrando que os esforços voltados ao tema têm surtido resultado positivo de qualidade.

A partir dessa informação, no quadro 1, identificamos os 29 periódicos e a quantidade de artigos encontrados em suas publicações que possuíam relevância ao estudo:

\section{Quadro 1 - Periódicos que apresentam artigos relevantes para a pesquisa}

\begin{tabular}{c|c} 
Nome da revista & № de artigos publicados \\
PSICOLOGIA \& SOCIEDADE & 22 \\
PSICOLOGIA: TEORIA E PESQUISA & 6 \\
PSICO & 5 \\
PSICOLOGIA EM ESTUDO & 4 \\
PSICOLOGIA: REFLEXÃO E CRÍTICA & 4 \\
ESTUDOS DE PSICOLOGIA & 4 \\
PESQUISAS E PRÁTICAS PSICOSSOCIAIS & 3 \\
PSICOLOGIA DA EDUCAÇÃO & 3 \\
PSICOPERSPECTIVAS: INDIVIDUO Y SOCIEDAD & 3 \\
FRONTIERS IN PSYCHOLOGY & 2 \\
ARQUIVOS BRASILEIROS DE PSICOLOGIA & 2 \\
PSICOLOGIA: CIÊNCIA E PROFISSÃO & 2 \\
INTERAMERICAN JOURNAL OF PSYCHOLOGY & 2 \\
PSICOLOGIA EM PESQUISA (UFJF) & 2 \\
SAUDE EM DEBATE & 1
\end{tabular}




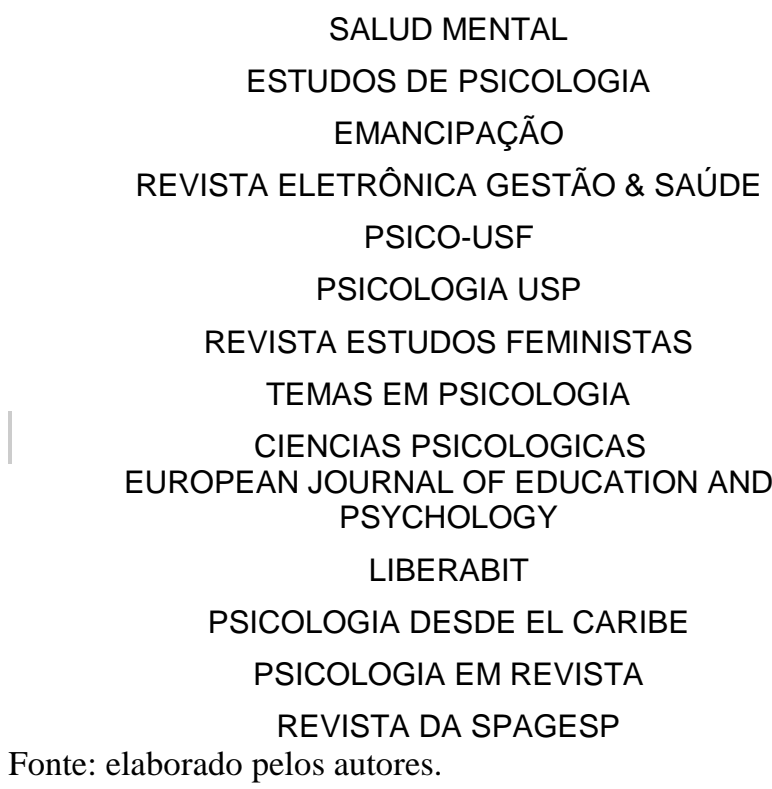

\begin{tabular}{|l}
1 \\
1 \\
1 \\
1 \\
1 \\
1 \\
1 \\
1 \\
1 \\
1 \\
1 \\
1 \\
1 \\
1
\end{tabular}

Os periódicos que mais apresentam artigos sobre o tema foram Psicologia \& Sociedade, que continha 22 artigos, seguida de Psicologia Social: Teoria e Pesquisa, com 6 artigos e o periódico PSICO, com 5 artigos. A desproporcionalidade da quantidade de artigos publicados entre as revistas demonstrou que, apesar de a maioria possuir qualificação alta como demonstrado na figura 1 , o fato de somente uma possuir maiores publicações demonstra como uma delas acaba abordando e recebendo artigos sobre o assunto.

Outro dado curioso é o idioma de publicação dos artigos encontrados. Na figura 2, a seguir, observou-se que a maioria é em português, ou seja, a maioria dos estudos que apresentam temática relacionada com PSCLA foram realizados no Brasil, seguido do espanhol e inglês.

\section{Figura 2 - Idioma de publicação dos artigos encontrados}




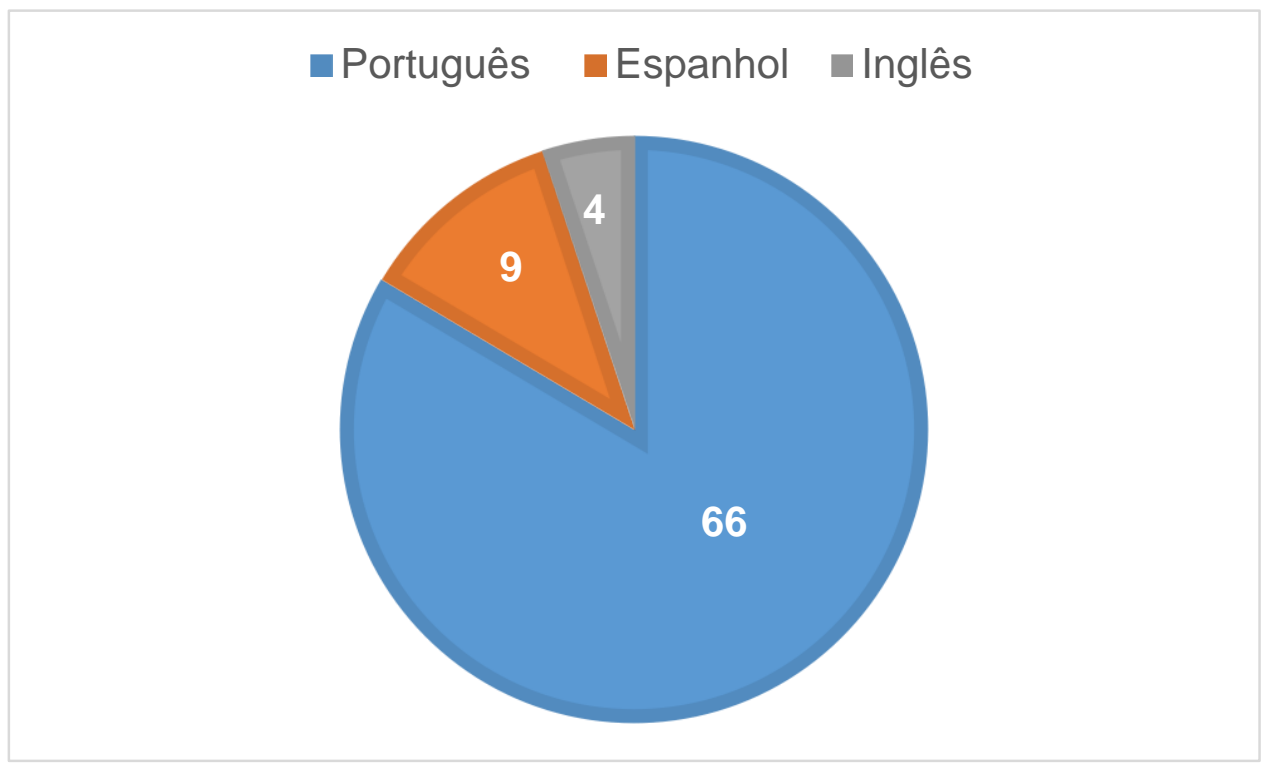

Fonte: elaborado pelos autores.

Observou-se que mais da metade dos 79 artigos estão em língua portuguesa, 9 em língua espanhola e somente 4 em inglês, evidenciando que, em sua maioria, os artigos são produzidos na América Latina e em minoria nos demais países ou traduzidos para publicações no exterior. Esses dados corroboram o fato de ter sido na América Latina que a PSCLA teve seu surgimento e se apresenta com maior força, como apontam os autores Nepomuceno et al. (2008), justificando as porcentagens apresentadas.

Os anos de publicações dos artigos encontrados começam a datar de 1997 e apresentam títulos publicados desde então. Na figura 3, apresentamos os anos com maiores números de publicações:

Figura 3 - Anos de publicações dos artigos 


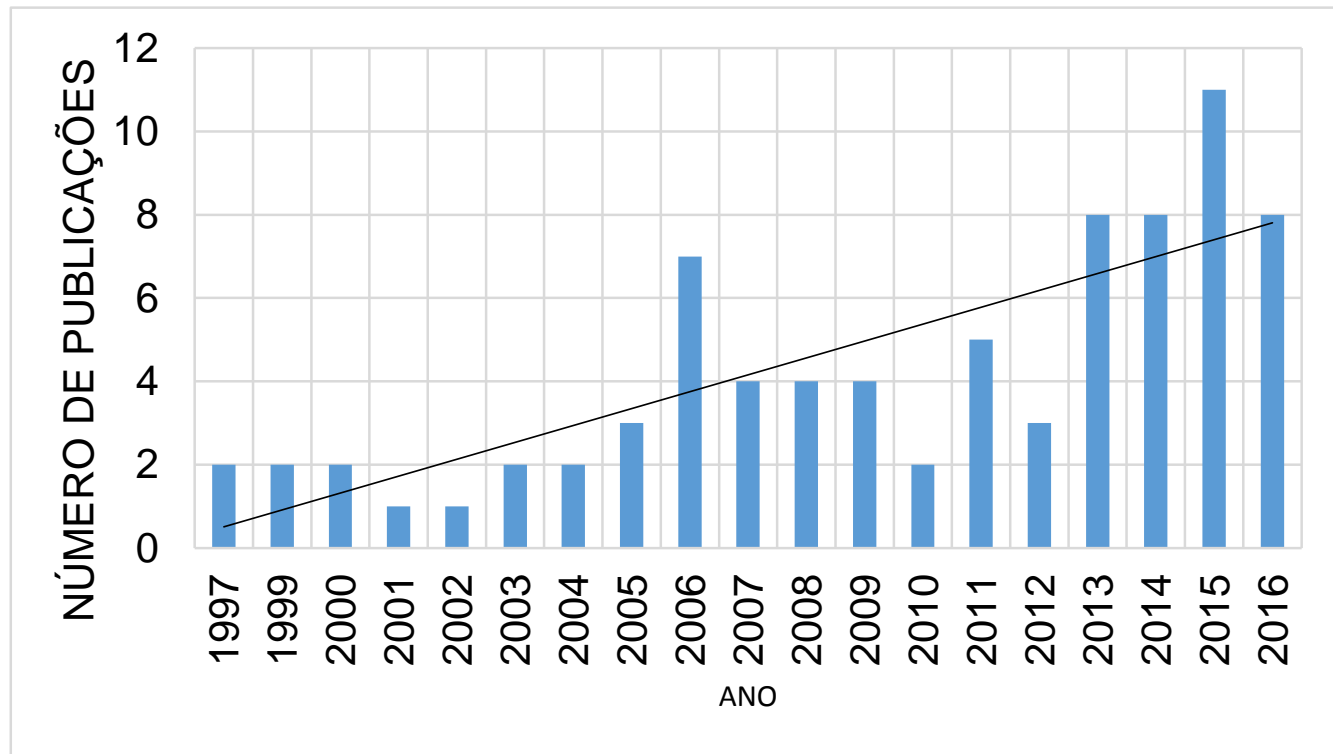

Fonte: elaborado pelos autores.

O ano que apresenta maiores publicações é 2015, totalizando 11 artigos publicados, seguido de 2013, 2014 e 2016, todos com oito publicações. Além disso, o ano de 2006 apresenta uma quantidade significativa de artigos publicados sobre o tema, um total de 7 artigos que, comparado aos demais anos, se sobressai nos anos 2000. Percebeu-se que não há uma linearidade ou crescimento constante dos números de artigos que abordam o tema: houve maiores picos sobre o assunto desde sua primeira aparição, porém o declínio de 27,27\% de 2015 para 2016 demonstra como o ano de 2015 foi atípico se comparado aos demais. Entretanto, é evidente que houve um crescimento importante de 2012 para 2013, que se manteve fortemente nos anos seguintes apesar da oscilação.

A partir da leitura dos 79 artigos, percebeu-se que a maioria dos estudos realizados é somente bibliográfico. Na figura 4, será possível visualizar a quantidade de estudos realizados: 


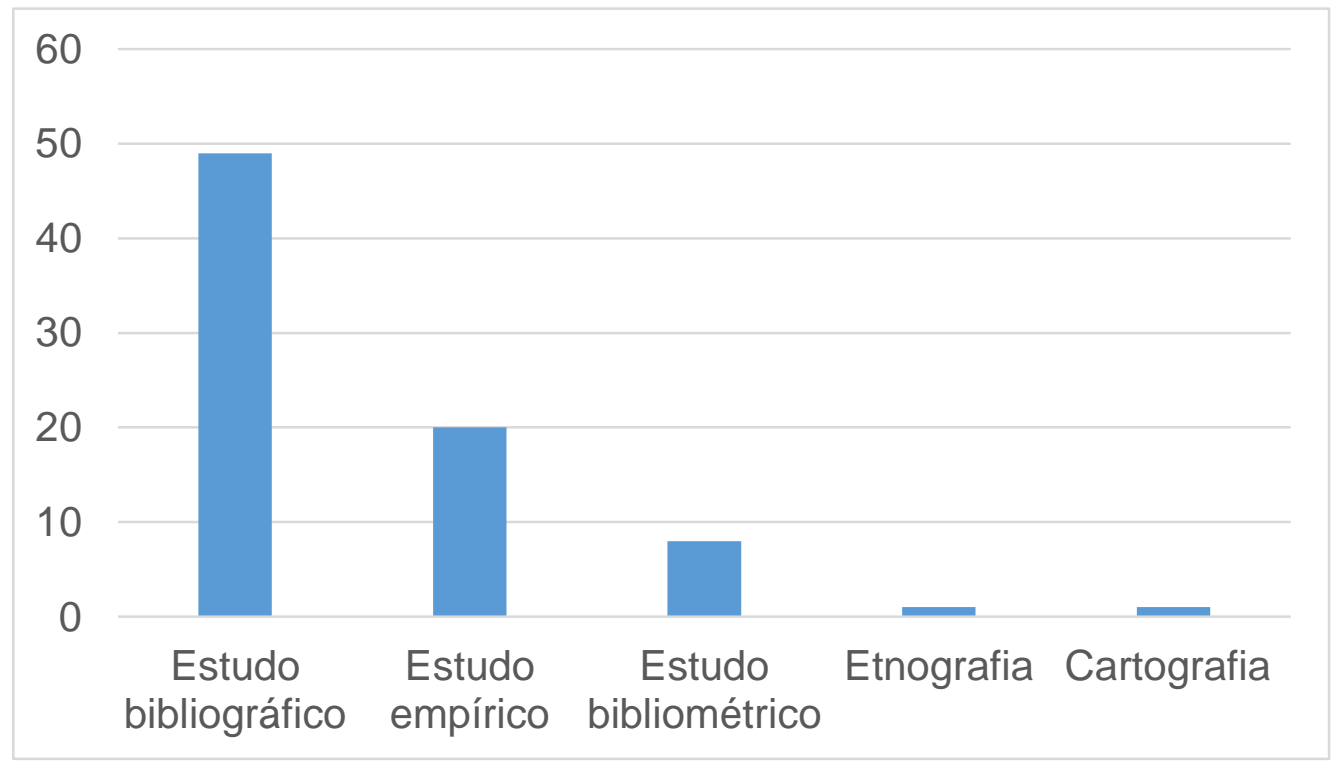

Fonte: elaborado pelos autores.

Dentre os 79 artigos, 49 deles são estudos bibliográficos, ou seja, a maioria discutiu as abordagens e os principais autores da área, sem incluir propostas intervencionistas ou pesquisa de campo. Logo depois, vêm os estudos empíricos: 20 deles apresentaram análises teóricas, mas também realizaram estudos em campo. Além disso, observou-se também outras formas de estudos dentro dos 79 artigos, tais como bibliométricos, etnografia e cartografia.

Esses dados demonstraram que, apesar do aumento considerável de publicações sobre os temas ao longo dos anos e a qualidade da pesquisa, somente $25,31 \%$ deles apresentam pesquisa de campo, apontando, talvez, para uma carência metodológica na área que pode ser decorrente de diversos fatores.

Outra característica encontrada na pesquisa é o fato dos artigos selecionados apresentarem diferentes formas de abordar a temática. Na figura 6, são apresentadas ambas as formas.

Figura 5 - Como o tema é abordado 


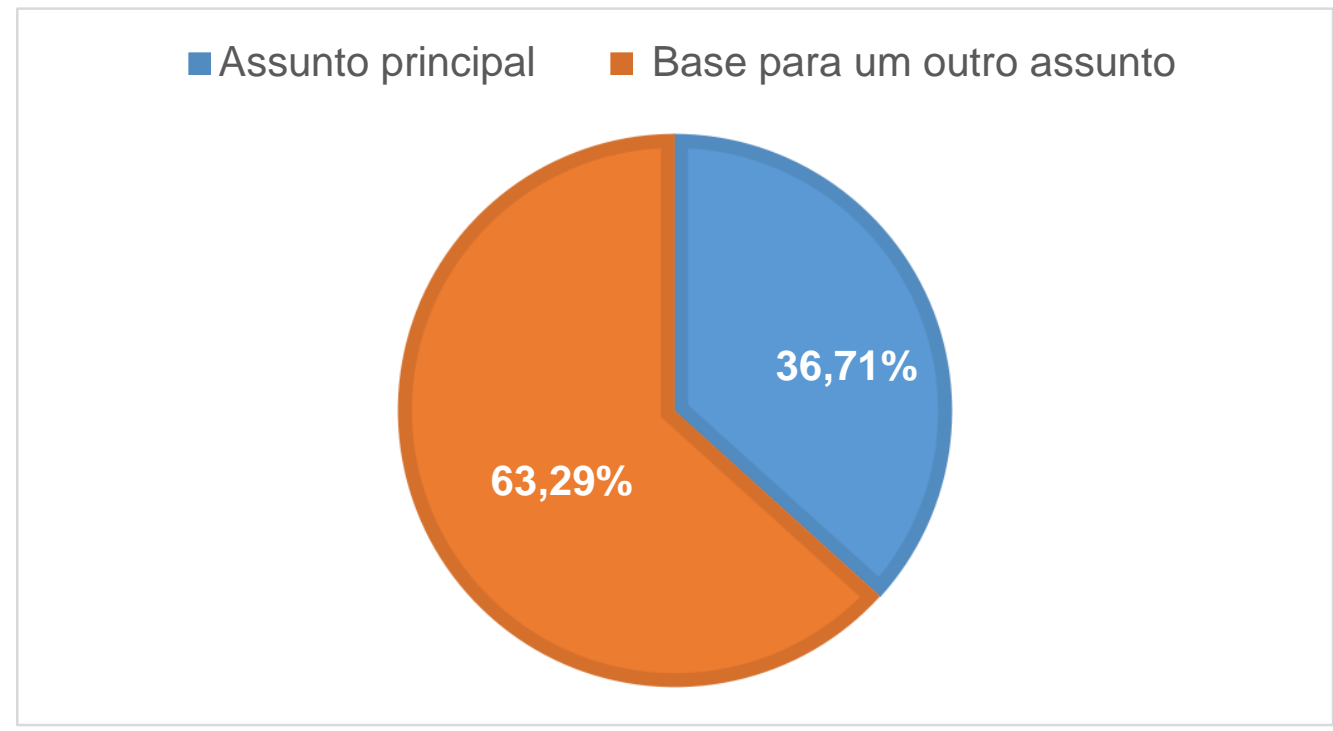

Fonte: elaborado pelos autores.

Nos artigos encontrados e analisados, percebeu-se que havia duas grandes formas de como o tema era tratado. Primeiro, em sua grande maioria, os autores utilizavam a base teórica da PSCLA para dar suporte a um segundo tema, utilizando-a como base para análise de dados coletados, como, por exemplo, estudos sobre a realidade de travestis e seus desafios. Outros estudos, porém, se concentravam unicamente na discussão e no desenvolvimento teórico da PSCLA. Ou seja, a maior preocupação dos autores tem sido compreender fenômenos sociais específicos ao invés de desenvolver teoricamente a temática.

No quadro 2, apresentamos os autores que mais publicaram sozinhos e os autores que mais publicaram em conjunto com outros autores:

Quadro 2- Lista de autores que mais publicaram os artigos

Autores que mais publicaram sozinhos Maria de Fatima Quintal de Freitas

Aluísio Ferreira Lima

Martha Traverso-Yépez

№ de artigos publicados

2

2

2

Autores que mais publicaram em conjunto com outros autores

Cleci Maraschin

Jaqueline Tittoni

2

Andréa Zanella

2

Léo Barbosa Nepomuceno

Verônica Morais Ximenes

Lurdes Perez Oberg

2

2

2

Fonte: elaborado pelos autores a partir de leitura dos artigos selecionados.

Em relação aos 20 artigos que realizaram estudo empírico, diferentes técnicas foram empregadas. As mais observados encontram-se no quadro 3. 
Quadro 3 - Técnicas mais encontrados nos artigos

\begin{tabular}{ll}
\hline Técnica utilizada & Quantidade de vezes utilizada \\
Observação e anotação em diário de campo & 5 \\
Questionário & 3 \\
Oficina com atividades lúdicas & 3 \\
Entrevista & 2 \\
Roda de discussão & 2 \\
Convivência no local e entrevistas & 2 \\
Plantão Comunitário & 1 \\
Teatro do Oprimido & 1 \\
Etnografia & 1 \\
\hline nte: elaborado pelos autores a partir de leitura dos artigos selecionados.
\end{tabular}

Observou-se que essas técnicas são aplicadas e colocadas no dia a dia da comunidade para entender melhor sua realidade. Observação e anotação em diário de campo consistem em permanecer no local escolhido por um determinado tempo sem interagir com os indivíduos, registrando suas impressões gradativamente. Os questionários são aqueles com perguntas, objetivas ou abertas, voltadas ao objetivo do estudo. As oficinas com atividades lúdicas são encontros corriqueiros promovidos pelo pesquisador com atividades mais descontraídas, no intuito de que o grupo comece a identificar o que o incomoda. As entrevistas são momentos de conversa individual e aberta, para ouvir os indivíduos da comunidade. Roda de discussão consiste em várias pessoas sentadas em roda para discutir um assunto que o pesquisador percebeu a necessidade de ser discutido. A convivência no local e entrevistas são como viver no local fazendo parte da realidade e coletando dados referentes à forma como as pessoas compreendem a realidade. Plantão Comunitário consiste em ficar no local em determinados horários para o caso de haver procura do estudo do pesquisador pela comunidade. $\mathrm{O}$ teatro do oprimido consiste em exercícios, jogos e técnicas de teatro para expor realidades e criar soluções. E, por fim, a etnografia, que consiste no fato do pesquisador se inserir na comunidade completamente, como se fosse um membro desta, no intuito de compreender profundamente aquela realidade, porém sem a intenção de transformá-la.

Observa-se, portanto, que os procedimentos metodológicos intervencionistas ainda são pouco empregados dentro no campo da PSCLA, sendo os estudos bibliográficos os de maior incidência. Além disso, foi possível identificar que, para estimular a percepção dos integrantes e a vontade de mudança, o pesquisador se utiliza de algumas técnicas como observações e anotações em campo, questionários e oficinas com atividades lúdicas. As entrevistas também são muito utilizadas para entender melhor a realidade do local estudado. Vale ressaltar que existem estudos que realizam somente uma das atividades, mas também existem aqueles que mesclam as diferentes técnicas para gerar o ambiente de intervenção. 


\section{CONSIDERAÇÕES FINAIS}

A partir dos dados coletados e de suas respectivas análises, com objetivo de identificar a incidência de propostas intervencionistas na PSCLA, alguns pontos merecem destaque. Primeiramente, o número de publicações sobre a temática, apesar de não ser alto tem apresentado um crescimento ao longo dos anos. Assim como o número de publicações, também é baixo o número de periódicos que publicam sobre a Psicologia Social Comunitária Latino-Americana.

O ponto forte é notar a alta classificação no Qualis desses periódicos (A1 e A2), o que permite pensar que os estudos realizados têm apresentado considerável consistência teórica ou teórico-metodológica, o que contribui positivamente para o desenvolvimento da temática. A fragilidade maior seria ter encontrado um alto número de publicações, porém com baixa classificação dos periódicos, uma vez que grande quantidade de publicações nem sempre representa ganho teórico ou metodológico, mas sim a profundidade desses estudos.

O fato da maioria dos artigos que abordam a PSCLA serem escritos em português, além de corroborar sua origem latina, também desperta um questionamento do quanto o campo científico estrangeiro tem se preocupado com as abordagens latinas da Psicologia Comunitária, e isso pode ser preocupante. $\mathrm{O}$ fato de uma vertente estar vinculada a demandas sociais e culturais específicas não impede que esta contribua com o refinamento da teoria. Talvez metodologicamente o ganho seja mais restrito à cultura em que se localiza o estudo. Entretanto, o ganho teórico pode ultrapassar essa especificidade social e cultural. Neste sentido, ressalta-se a importância de que mesmo se tratando de PSCLA, estes estudos deveriam alcançar as mais diferentes nacionalidades, serem escritos e publicados em diferentes línguas.

Se a maior parte dos artigos encontrados foram teóricos e, dentre estes, somente uma minoria concentrou-se exclusivamente na PSCLA, é possível pensar em uma carência metodológica no campo. Não que a abordagem não possua um aparato metodológico, pois é fato que possui, porém, sua implementação ainda não se encontra consolidada, o que pode ser visto como um aspecto natural, tendo em vista que se trata de uma abordagem relativamente jovem. O fato de existirem obras de renome organizando teórica e metodologicamente o campo não significa que essa pauta esteja vencida; ainda é preciso um longo caminho de testagem e consolidação dessas práticas, o que demanda, além de um profundo conhecimento teórico, um exercício prático constante do pesquisador que vai ao campo. É menos 
complicado para o pesquisador conhecer e diagnosticar do que intervir e transformar uma realidade.

Não é à toa que os artigos empíricos se utilizaram mais de procedimentos de diagnóstico do que de intervenção propriamente dita. Neste ponto é preciso pensar que o diagnóstico geralmente é a etapa que antecede a intervenção, o que retira deste dado sua característica negativa, como se procedimentos não intervencionistas não fossem válidos, pois eles podem ser um considerados uma condição necessária para a intervenção.

Também é possível relacionar esta maior incidência de discussões teóricas e pesquisas de campo mais voltadas ao diagnóstico do que a intervenções, ao fato de que esta é uma característica própria da pesquisa brasileira: uma pesquisa de curto prazo, provavelmente relacionada aos limitados prazos das pesquisas stricto sensu, e também à falta de investimentos públicos em pesquisas científicas. Estes fatores podem contribuir com uma pesquisa sempre curta, sem tempo e recursos necessários para ser continuada e aprofundada. É possível que existam casos, por exemplo, em que após a fase de diagnóstico, quando deveriam acontecer novas inserções no campo para intervenções com vistas à transformação social, o pesquisador é levado a encerrar suas atividades.

Estes questionamentos levantados a partir dos dados obtidos, longe de serem conclusivos, podem contribuir com a temática na medida em que apontam para a necessidade de um aprofundamento metodológico do campo. Não só no campo da PSCLA, bem como para os Estudos Organizacionais, é preciso considerar a pesquisa intervencionista como uma possibilidade de transformação social.

Investir em diagnósticos é fundamental para o avanço teórico, porém é preciso dar um passo em direção à transformação, pesquisas que intervenham na realidade, seja ela organizacional ou social. É preciso ir além do diagnóstico, passar para a próxima fase, implementando, testando e consolidando ferramentas. Se contentar com o diagnóstico é como começar várias vezes o mesmo jogo sem passar da primeira casa do tabuleiro; é preciso avançar as casas e jogar o jogo até o final.

Quanto às limitações do estudo, faz-se necessário esclarecer que a busca de periódicos apenas na plataforma Sucupira é a principal delas. Caso um futuro estudo seja realizado em novas plataformas, é possível que outros pontos relevantes apareçam.

\section{REFERÊNCIAS}

AGUIAR, S. G. ; RONZANI, T. M. Psicologia social e saúde coletiva: reconstruindo identidades. Psicologia em pesquisa. Juiz de Fora, v. 1 (02), p.11-22, jul./dez.2007 
ANDRADE, L. A.; VELOSO, T. M. G. Arte e saúde: mental: uma experiência com a metodologia participativa da Educação Popular. Pesquisas e Práticas Psicossociais. São João del-Rei, v. 10(2), p.79-87, jul./dez. 2015

ARENDT, R. J. J. Psicologia comunitária: Teoria e metodologia. Psicologia: Reflexão e Crítica. Por Alegre, v. 10, n.1, 1997

AZEVÊDO, A. V. S.; PARDO, M. L. B. Formação e atuação em psicologia social comunitária.Psicologia em Pesquisa. v. 8(2), p.200-210, jul./dez. 2014

CÂMARA, R. S.; FRANCISCATTI, K. V. S. A Psicologia social de Theodor Adorno na produção brasileira (1984-2015). Psicologia \& Sociedade. São João Del Rei, v. 28(3), p.537551,2016

CANTERA, L. M.; CANTERA, F. M. El auto-cuidado activo y su importância para Psicología Comunitaria. Individuo y Sociedad. v. 13, n. 02, p.88-97, 2014

COIN-CARVALHO, J.; OSTRONOFF, V. H. Cuidado e transformação social: avaliação da implantação do plantão comunitário no Complexo da Funerária. Estudos de Psicologia. São Paulo, v. 19(2), p.89-156, abr./jun. 2014

CRUZ, R. N.; STRALEN, C. J. A Produção de conhecimento na psicologia social brasileira: um estudo descrito a partir da revista Psicologia \& Sociedade (1986-1992). Psicologia \& Sociedade. Belo Horizonte, v. 24(1), p.227-239, 2012

FREITAS, M. F. G. (In)Coerência entre práticas psicossociais em comunidade e projetos de transformação social: aproximações entre as Psicologias Sociais da libertação e comunitária. Psico. Curitiba, v. 36, n. 1, p.521-532, jan./abr.2015

FREITAS, M. F. G. Práxis e formação em Psicologia Social Comunitária: exigências e desafios ético-políticos. Estudos da Psicologia. Campinas, v. 32(3), p.521-532, jul./dez.2015

GOUVEIA, V. V. Psicologia social como ciência e prática: O que pensam pesquisadores brasileiros? Psicologia: Teoria e Pesquisa. João Pessoa, v.3, n.4, p.491-500, out./dez.2015

LOPES, L. P.; NASCIMENTO, A. R. A. O que faz uma psicologia social? Intervenção na psicologia social brasileira. Psicologia \& Sociedade. Belo Horizonte, v. 28(1), p.14-25, 2016 
MACIEL, T. B.; ALVES, M. B. A importância da psicologia social comunitária para o desenvolvimento sustentável. Pesquisas e Práticas Psicossociais. São João del-Rei, v. 10(2), p.272-282, jul./dez. 2015

MENESES, H. S. et al. Dando voz, papel e pincel para crianças na unidade básica de saúde: um relato de experiência. Gestão \& Saúde. v. 05, n. 02, p.643-653, 2014

NEPOMUCENO et al. Por uma psicologia comunitária como práxis de libertação. Psico. Fortaleza, v. 39, n.4, p.456-464, out./dez. 2008

MONTERO, M. Introducción a la psicología comunitaria. Desarrollo, conceptos y procesos. Editorial Paidós: Buenos Aires. Argentina, 2004.

NEPOMUCENO et al. Por uma psicologia comunitária como práxis de libertação. Psico. Fortaleza, v. 39, n.4, p.456-464, out./dez. 2008

OBERG, L. P.; VILHENA, J. Psicologia Comunitária: a clínica ampliada na localidade de Muzema .Psico. Rio de Janeiro, v. 42, n.3, p.408-415, jul./set. 2011

PICHETH, S.; CASSANDRE, M.; THIOLLENT, M. Analisando a pesquisa-ação à luz dos princípios intervencionistas: um olhar comparativo. Educação, Porto Alegre, v. 39, n. esp. (supl), p. s3-s13, 2016.

RIBAS JR, R. C. et al.A psicologia social no Brasil (1986-2006). Uma avaliação bibliométrica baseada no PsycINFO. Revista Interamericana de Psicologia. Rio de Janeiro, v. 43, n.3, p.532-540, 2009

SILVA, C. V. P. Psicologia latino-americana: desafios e possibilidades. Psicologia: Ciência e Profissão. Salvador, v. 33, n. esp, p.32-41, 2013.

STACHIU, M.; TAGLIAMENTO, G. Coaching de carreira e psicologia social comunitária: Análise de uma intervenção. Temas em Psicologia. Curitiba, v. 24, n. 3, p.791-804, 2016

VIDAL, A. S. Manual de Psicologia Comunitária: um enfoque integrado. Ediciones Pirámide. Madrid, 2007. 
VIEIRA-SILVA, M. Práticas em psicologia comunitária e processo de mobilizalção social: provocações para um debate. Pesquisas e Práticas Psicossociais. São João del-Rei, v. 10(2), p.292-300, jul./dez. 2015.

Recebido em 08/12/2017. Aceito em 02/04/2018.

Publicado em 02/04/2018. 